\title{
THERMAL ANALYSIS OF NICKEL ALLOYIAL2O3/TIO2 HYBRID METAL MATRIX COMPOSITE IN AUTOMOTIVE ENGINE EXHAUST VALVE USING FEA METHOD
}

\author{
J. Kumaraswamy', Vijaya Kumar², G. Purushotham³ ${ }^{3}$ R Suresh ${ }^{4}$
}

\begin{abstract}
The current research aims to develop a hybrid metal matrix composition that focuses on the nickel alloy and its thermal properties. The different temperature ranges are used to analyze the function of MMCs such as thermal conductivity and coefficient of thermal expansion. This paper addresses the thermal properties obtained from a series of $\mathrm{Al}_{2} \mathrm{O}_{3}$ and $\mathrm{TiO}_{2}$ reinforced nickel alloy (ASTM A494 M), with dispersed particle sizes ranging from 40-45 microns of $\mathrm{Al}_{2} \mathrm{O}_{3}$ and 1-5 microns of $\mathrm{TiO}_{2}$. The quantity of the $\mathrm{Al}_{2} \mathrm{O}_{3}$ addition varies from 3-12 weight $\%$ and 9 weight $\%$ of $\mathrm{TiO}_{2}$ unvarying in the stages of three weight percentages. The microstructural investigation states that, because of the stir casting on the vortex, the distribution of reinforcements is uniform with a strong bond. With the increase in $\mathrm{Al}_{2} \mathrm{O}_{3}$ and $\mathrm{TiO}_{2}$ content in HMMCs, a thermal property is found to diminish significantly. The results indicate that the reinforcements have a major effect on the thermal expansion coefficient as well as on the thermal conductivity of the hybrid composites being produced. Various types of microstructural have been performed using electron microscopy scanning and EDAX. The limited examination of the exhaust valve of the I $\mathrm{C}$ engine shows that the nickel combination composites can be utilized as a substitute for the present valve material (Ni-Cr alloy steel). All tests acted in this investigation meet ASTM specifications.
\end{abstract}

Keywords: Nickel alloy, Hybrid metal matrix composites, Thermal conductivity, Heat flux, Finite element analysis

\section{INTRODUCTION}

Constant innovation and developing business conditions requisites an expansion in innovative work needs for the creation of composite materials with various properties as of late. This expansion has led to the development of composite materials with a low explicit weight. Since they can be made in different mixes with the ideal degrees of solidarity, high strength, high-temperature resistance and good protection against oxidation and wear of composite materials have been used extensively. Due to high fatigue strength, corrosion resistance, electrical and thermal properties the Ni-based metal matrix composites used windily in automotive consumer goods, electrical and electronic industries [1-3]. Generally speaking, particle-reinforced metal matrix (MMC) compositions are excellent because they have isotropic properties compared to continuous composite material reinforcement. Numerous scientists contend that the nickel composite has greater advantages over different materials, including higher hardness, wear obstruction; improved break split transmission, and improved smaller scale creep execution. This can be accomplished by standard metal handling strategies notwithstanding the development of moderate reinforced nickel combinations and can be kept utilizing customary hardware. Previous experiments have been performed to measure and study the mechanical behavior of nickel and its alloys. For decades, many studies have been done on the thermal properties of metal grid composites as they are utilized as bundling materials in electronic applications [4-5]. The CTE is compatible with the rest of the devices by separating the volume fraction as per the steps involved and the heat-induced stress is reduced through the process of temperature. Where-heat-induced stress occasionally contributes to system malfunction, this factor enhances its reliability. Thermal conductivity is important, particularly in high-energy devices because a large amount of heat must also be absorbed by the substratum [6-7]. The linear coefficient of thermal expansion (CTE, $\alpha$, or $\alpha 1)$ is a material property that indicates the extent to which material exponents exist in their heating phase. The

This paper was recommended for publication in revised form by Regional Editor Emre Alpman

${ }^{1}$ Department of Mechanical Engineering, R.L. Jalappa Institute of Technology, Doddaballapur-561203, Karnataka, India

${ }^{2}$ Department of Mechanical Engineering, UBDT College of Engineering, Davangere-577004, Karnataka, India

${ }^{3}$ Department of Aeronautical Engineering, Mangalore Institute of Technology \&Engineering, Moodabidre-574225, Karnataka, India

${ }^{4}$ Department Mechanical and Manufacturing Engineering, M.S. Ramaiah University of Applied Sciences, Bangalore-560058, India

*E-mail address: surershchiru09@gmail.com, suresh.me.et@msruas.ac.in

Orcid id: 0000-0002-6956-9751, 0000-0003-4264-4763, 0000-0003-3856-3995, 0000-0002-7035-2867

Manuscript Received: 05 June 2020, Accepted: 17 September 2020 
thermal expansion of standard dimensional structures is proportional to the temperature change, over limited temperature ranges. Thermal expansion is used in pneumatic strips to produce thermometers but when the structural component is heated and kept at a constant rate, it can cause dangerous stresses. The coefficient of thermal expansion is known as the partial temperature increase, as the unit increases [8-9]. When the temperature is the true expansion coefficient (thermal expansion coefficient) then the exact meaning varies depending on the temperature. The actual coefficient is related to the temperature tangent to the temperature curve but the average coefficient between the two points of the graph is calculated from the slope of the wire. There may also be variations in the CTE values depending on the term used. Heating or cooling influences the material body dimensions, resulting in a volume transition. Volume changes can be determined by:

$$
\Delta V / V_{o}=\alpha V \Delta T
$$

The original $\mathrm{V}$ and $\mathrm{Vo}$ are the frequency changes and the new volume changes, respectively, $\alpha \mathrm{V}$ is the volume thermal expansion coefficient. The value of $\alpha \mathrm{V}$ is anisotropic in many materials; it depends on the crystallographic pathway. For isotropic thermal expansion materials, $\alpha \mathrm{V}$ are about $3 \alpha 1$.Another important characteristic is the coefficient of thermal expansion (CTE), which is defined as a change in the temperature length. The CTE is sufficient if the thermal load dominates the thermostatic change or the device is weakened. The effectiveness and future of electronic components depend on the high dispersion of heat and CTE. Miniaturization of electronic components, highperformance microchips, power loss, and a low coefficient of thermal expansion (CTE) are important components of the modern electronics industry. The silhouette and low CTE thermal conductivity can be achieved with the clever combination of two or more products. Many of the thermal conductive metals like copper or aluminum are packed with low CTE fillers like carbon fiber, $\mathrm{Al}, \mathrm{SiC}$, diamonds. Limited shifts in amplitude with minimal thermal stress must be indispensable in compositions designed for thermal management. The composites' thermal properties are largely subordinated to the filler and matrix meter and have correlated properties [10-13]. The use of materials for thermal management depends on the expansion and capacity of preserving thermal conductivity, heat dispersion, thermostat, and its basic characteristics. The conductivity of a metallic object depends on the speed of the electrons in the metals. The thermal conductivity in non-metallic crystals or ceramics is a duplex phenomenon, which depends on the atomic mass, the interatomic bond, and crystal composition. The movement of electrons and photons matches their disinfection, but the metal creates additional electrons. Nevertheless, these materials have a higher expansion coefficient due to the favorable inter-atomic comparison of ceramics compared to those materials [14]. A materials thermal conductivity is proportional to the varying electrical conductivity and is given by:

$$
k=L \sigma T
$$

Where $\mathrm{k}$ is the thermal conductivity, $\sigma$ is the electrical conductivity and $\mathrm{L}$ is Lorentz value.

Microstructural design and synthesis processes were performed to develop enhanced properties including increased height and fatigue strength, increased moisture strength, optimization, and thermal conductivity, wear rate, and expansion of the thermal coefficient. Such properties are seen in hybrid MMCs which is not seen in conventional materials for a range of modern applications. Matrix alloys in cast hybrid MMCs strengthen to form the bulk of the matrix in the confined space between the reinforcing phases. The freezing microstructure of the matrix has been simplified because of the presence of particles, providing a potential pathway for arbitrary solvent microdecomposition within the microstructure, bulk separation of casting reinforcement, and grain size in the matrix. Matrix microstructure is a significant contributor to the nature of the relationship between the underlying strengthening, reinforcement, and the properties of the combined HMMCs matrix [15]. Micro-isolation and nano segregation, the reaction on solidification, nucleation, and flux around reinforcement, the formation of secondary and secondary phases around reinforcement affect micro-isolation and strengthening of nanoparticles within the microstructure of the matrix. For cementing during the preparation of composites, fluid metal is blended in with the fortifying procedure, and set in a form. Cementing procedures of the composite blend can be isolated into two primary classes: the combination of the vortex and the melting of the penetration while stirring. The reinforcement phases are combined to melt and the mixture 
is stirred by using either a mechanical stirrer or a high-intensity ultrasound instrument. Melt particle slurry can be developed by traditional foundry methods such as gravity, pressure nozzle or centrifugal casting, or by modern techniques such as press casting (liquid forging), spray co-deposition and melt spinning or laser-made mesh forming. Mixing and pouring with stirring is now used on a large scale in the manufacture of particle-reinforced MMCs. The various metals such as iron, magnesium, steel, and copper are used as the foundation and a large number of reinforcements such as $\mathrm{SiC}$, graphite, $\mathrm{SiO}_{2}, \mathrm{Al}_{2} \mathrm{O}_{3}, \mathrm{Si}_{3} \mathrm{~N}_{4}$, and $\mathrm{ZrSiO}_{4}$ are used. Examination of cast composites has brought substantial insight into the solidification of traditional monolithic castings, notably concerns related to fluidity, viscosity, nucleation, progress, particle settling, and inclusion-pushing impacts. Microstructure also has significant significance in the behavior of thermal conductivity. Microstructural modification can keep the thermal conductivity under control. This can be done by modeling studies using real images of the microstructure. To utilize the finite element (FE), notwithstanding, the individual characteristic thermal conductivity estimations of the stages must be determined [16-17]. In the present study, a finite element strategy is applied to study the impact of the volume gain proportion on the temperature conveyances of crossover $\mathrm{Al}_{2} \mathrm{O}_{3} / \mathrm{TiO}_{2}$ composites that are manufactured by sand molding.

\section{MATERIALS AND METHODS}

This research focuses, on the composites formed by alloy and hybrid metal matrix with reinforcements of particles $\mathrm{Al}_{2} \mathrm{O}_{3}$ and $\mathrm{TiO}_{2}$. Nickel alloys include $63.34-74 \%$ nickel, $26-33 \%$ copper, $3.5 \%$ iron, $1.25 \%$ silicon, $1.5 \%$ manganese, $0.5 \%$ cobalt, $0.3 \%$ mercury, $0.03 \%$ sulfur and $0.03 \%$ phosphorus. But their nickel and nickel-based mixtures are used in a range of severe conditions, including corrosive climates, high temperature, high endurance, high pressure, metallurgical durability, hardness, and weldability.

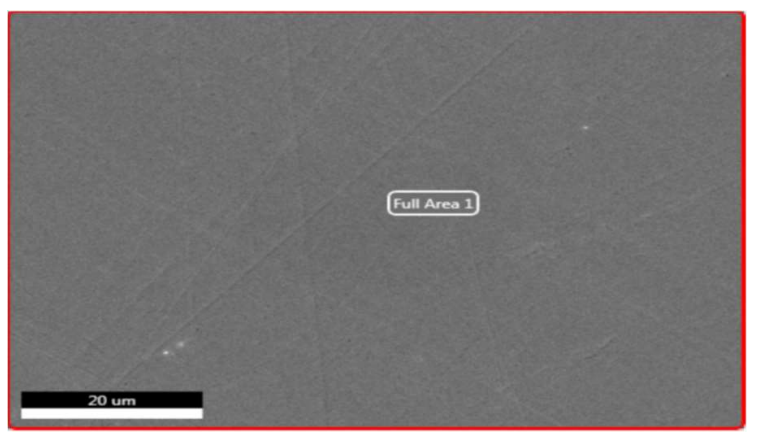

\section{eZAF Smart Quant Results}

$\begin{array}{ccc}\text { Elements } & \text { Weight } \% & \text { Atomic \% } \\ \text { FeK } & 2.23 & 2.41 \\ \text { NiK } & 60.48 & 62.17 \\ \text { CuK } & 37.29 & 35.42\end{array}$

Selected Area 1

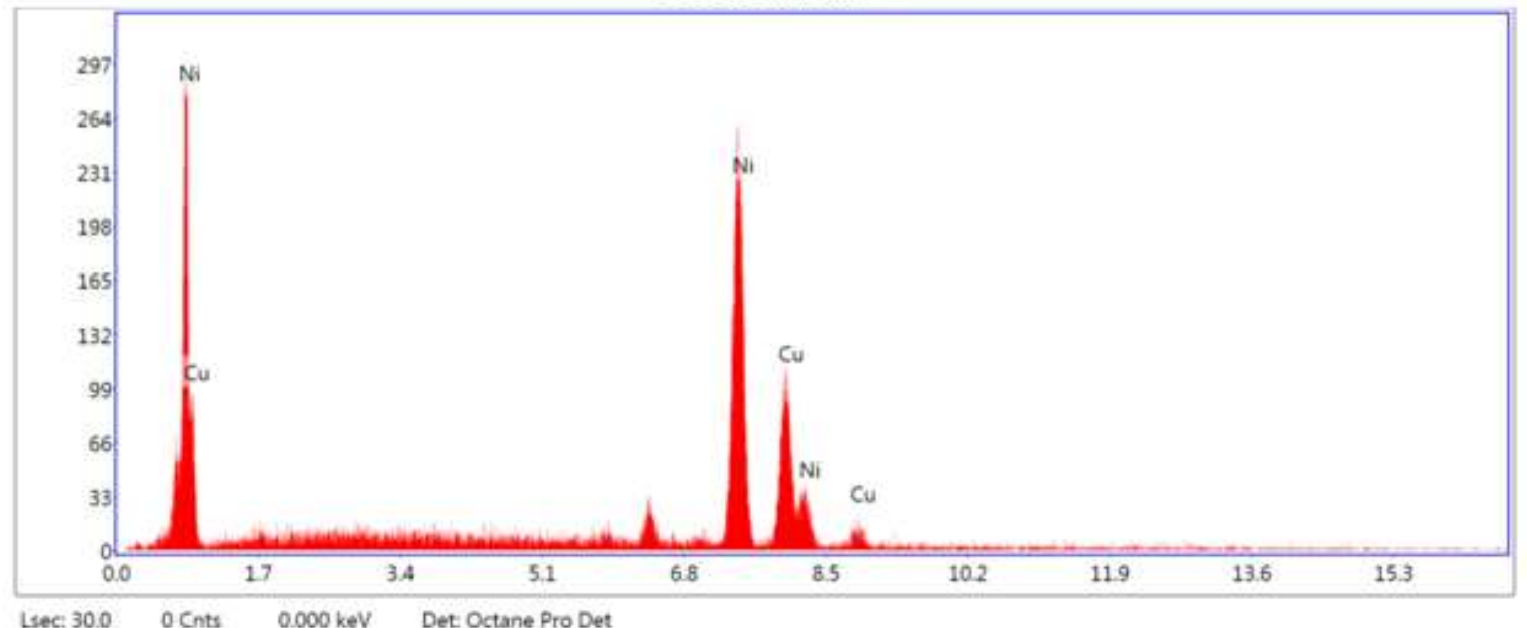

Figure 1.SEM and EDAX analysis of the nickel alloy matrix. 
Nickel matrix alloy was melted and the hybrid composites were being produced in an induction furnace with a crucible capacity of around $20 \mathrm{~kg}$. The induction furnace was preheated at $600{ }^{\circ} \mathrm{C}$ for 30 minutes and the fuel was then pumped with a carbide impeller which sprayed in plasma to prevent reactions in aluminum and iron. $\mathrm{TiO}_{2}$ particles with an average size of $5 \mu \mathrm{m}$ and $\mathrm{Al}_{2} \mathrm{O}_{3}$ particles with an average size of $45 \mu \mathrm{m}$ were added in a simulated vortex. With a purity of about 99.8 percent and a density of $4.2 \mathrm{~g} / \mathrm{cm}^{3}, \mathrm{Al}_{2} \mathrm{O}_{3}$ particles were polycrystalline and irregular in form. $\mathrm{Al}_{2} \mathrm{O}_{3}$ particle proportions $(3 ; 6 ; 9 ; 12$ weight percentage) for possible bearing applications with apparent reinforcement of various additional $\mathrm{TiO}_{2}$ particle sizes (constant 9 weight percent) were used. The mixture was continuously added until a mushy state is reached by the combined solubility. The stirring of titanium dioxide and aluminum oxide particles in the Ni alloy matrix was continued for 10 minutes to strengthen the mechanical lock. The temperature was allowed to reach $1455^{\circ} \mathrm{C}$ after mixing, and the mixture was stirred for another 20 seconds to avoid depositing $\mathrm{TiO}_{2}$ and $\mathrm{Al}_{2} \mathrm{O}_{3}$ particles. It was then poured in a sand mold which has preheated to $600{ }^{\circ} \mathrm{C}$. The freezing process was completed in less than $50 \mathrm{MPa}$. To avoid melting and oxidation of the reinforcing particles, the reinforcing particles were added and mixed in a safe argon atmosphere, as shown in Figure 2.

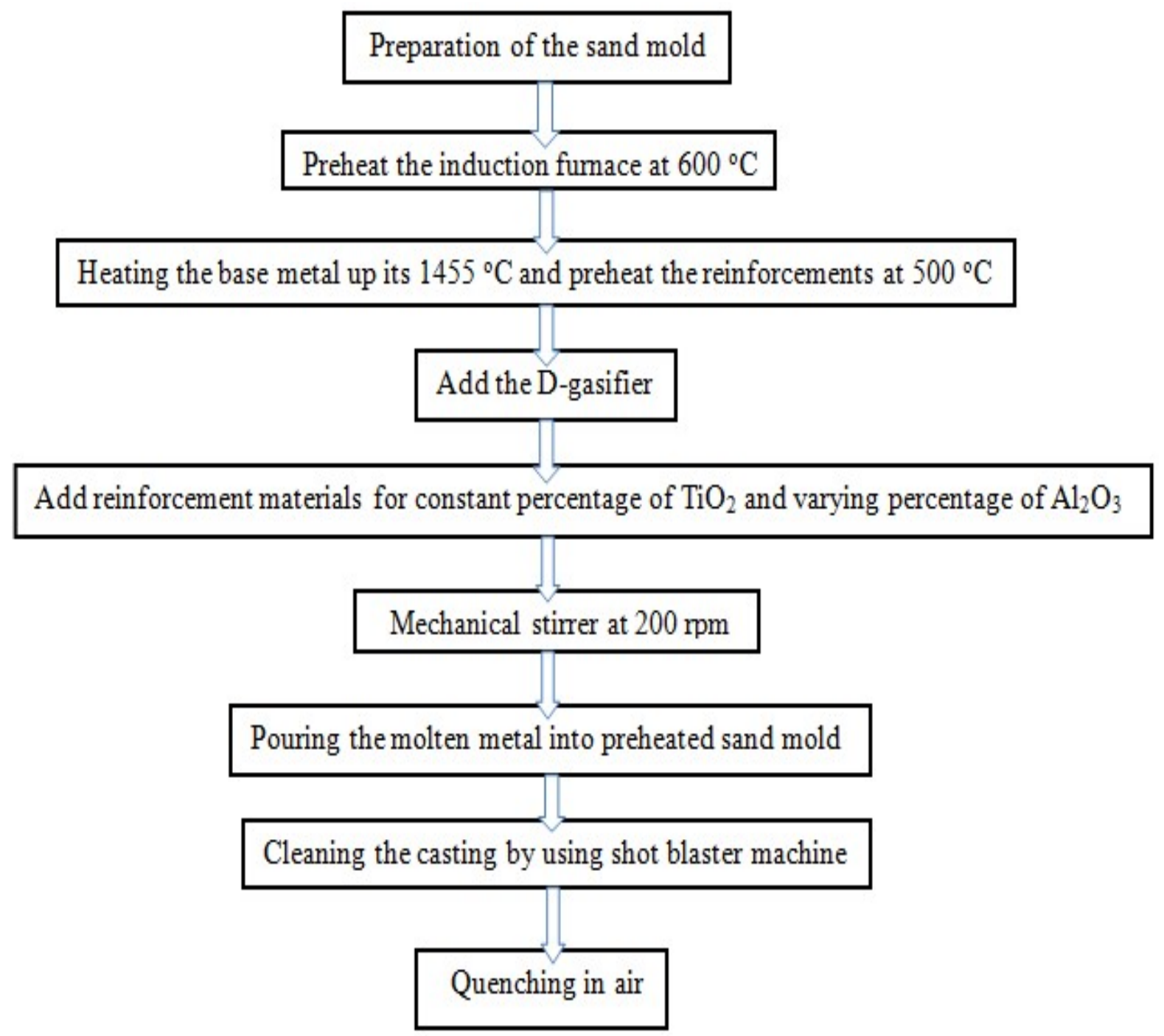

Figure 2. Flow chart of sand mold casting for hybrid Ni alloy metal matrix composites. 


\section{Testing of hybrid composites}

The thermal expansion and CTE tests were carried out with a test quality dilatometer system (Anter-Unithen Model-1161 V) for the prepared samples ( $8 \mathrm{~mm}$ diameter x $50 \mathrm{~mm}$ length). The warming and cooling rates were kept at $5{ }^{\circ} \mathrm{C} / \mathrm{min}$ and were constantly constrained by an information handling gadget dependent on a PC. The thermal conductivity was determined utilizing a laser streak technique with a thermal conductivity meter (Netzsch LFA-447) between $50{ }^{\circ} \mathrm{C}$ and $300{ }^{\circ} \mathrm{C}$ temperature range. For thermal conductivity testing, the sand cast composites were into a cylinder of $8 \mathrm{~mm}$ diameter and $50 \mathrm{~mm}$ length from the disk samples. Composites were machined to prepare specimens for analysis of the microstructure. Hybrid composites products were manufactured to ASTM testing standards under different conditions. Microstructure characterization studies were conducted using optical microscopy and electron microscopy scanning (SEM, Tescan-Vega 3 LMU) with energy diffusion spectroscopy (EDS) to observe the movement of reinforced particles in composites.

\section{RESULTS AND DISCUSSION}

\section{Microstructures of Nickel Alloy Composites}

Composite characterization refers to the wide-ranging and general method by which composite structure and properties are analyzed and evaluated to ensure materials meet performance criteria for application. In scanning electron microscopy, the figures on the slicked pattern were observed systematically, with different magnifications and measurements. Figure 3 shows the alloy matrix compositions of Ni-alloy, Ni-alloy $+9 \% \mathrm{Al}_{2} \mathrm{O}_{3}+9 \% \mathrm{TiO}_{2}$. For transparency, the microstructures of hybrid composites for the safe reinforcement of $\mathrm{TiO}_{2}$ particles $(9$ weight \%) for each $\mathrm{Al}_{2} \mathrm{O}_{3}$ particle size are shown in the figures $\left(3 \mathrm{a} \& \mathrm{~b}\right.$ ). In microstructure, the particles of $\mathrm{Al}_{2} \mathrm{O}_{3}$ and $\mathrm{TiO}_{2}$ are instinctive, without fractures and holes. Estimated porosity ranged between 1.5 and 2.5 percentage points for the invited hybrid composites. The interdendritic segment is due to condensation of moving particles and they are located selectively in the eutectic regions during freezing. Particulate involvement in matrix molecules greatly improves the microstructure, weakening the roughness during freezing of the primary dendrites. $\mathrm{Al}_{2} \mathrm{O}_{3}$ particles mainly pass through primary dendrite boundaries of Ni-alloy although some are found in grains of aluminum. The porosity found in the cluster region of $\mathrm{Al}_{2} \mathrm{O}_{3}$ particles was frequently observed after small scale engraving. Laboratory experiments have found that the addition of $\mathrm{TiO}_{2}$ particles conveyed an equivalent effect on the addition of $\mathrm{Al}_{2} \mathrm{O}_{3}$. For both the principal nickel alloy dendrites and the eutectic aluminum oxide, raising the quantity of $\mathrm{TiO}_{2}$ in the composite matrix improved grain refinement. On the silicon surface, there was a processing of microstructures throughout the $\mathrm{Al}_{2} \mathrm{O}_{3}$ particles.

The microstructure has a viscous solution from the nickel alloy, with some unspecified non-metallic additions. The combined surface appeared to be like small boulders, and at 500X, the whole dendritic form was visible. Microstructural qualities of hybrid nickel combination composites rely basically upon the idea of the lattice amalgam fortifications, their holding, and their dissemination. The present discussion for the investigation relies upon 9 weight $\%$ fortresses since properties (both mechanical and thermal) are up to 9 weight \% (perfect). On further augmentation in the stronghold substance (to 12 weight percent) it was seen that the care group improvement happens which selfdestructs the mechanical properties. Microstructural investigations of hybrid composites containing 9 weight $\%$, level of fortifications uncovered a reliable conveyance of fortifications without bunch arrangement alongside great interfacial support network respectability (holding) and noteworthy grain refining without small scale porosity (Figure 3). This is due to the distinction between the thickness of the network combination reinforcements, the preheating of the reinforcements for good wetting properties, and the blending of the vortex.

Microstructural investigations of the heat-treated examples have also revealed that the grid was completely recrystallized. Grain fortifications of the composites because of heat treatment are principally ascribed to the way that $\mathrm{Al}_{2} \mathrm{O}_{3} / \mathrm{TiO}_{2}$ particulates nucleate in nickel grain during directional cementing which confirms the development of recrystallized nickel grains. Utilizing filtering electron magnifying lens for broken surfaces to investigate the trustworthiness of the particulate-lattice interface, interfacial respectability among grid and fortifications was likewise assessed. Here, SEM concentrates additionally uncover that true to form, which shows solid security between the interfaces. Thus, microstructural contemplates uncovering that, in this exploration, quicker rate of heating during cementing of the composite prompts solid holding of the fortifications and framework. In any case, the consequences 
of microstructural investigations of hybrid nickel alloy composites didn't uncover any micro porosity or pit shrinkage or there was no proof of some other imperfections.
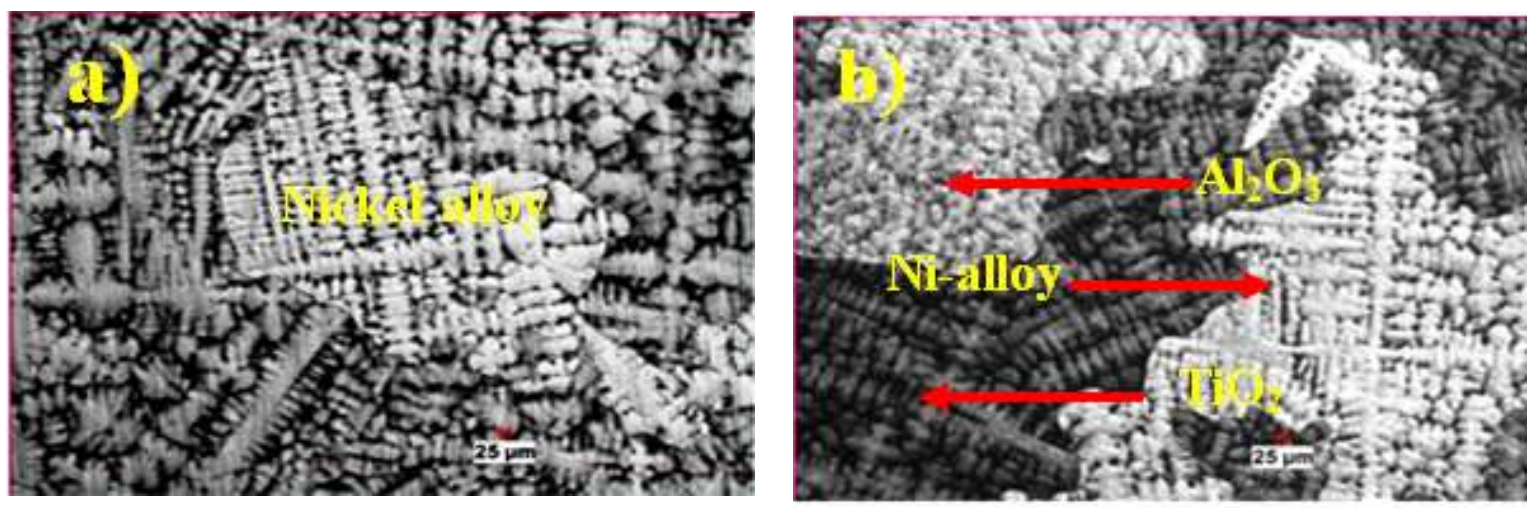

Figure 3. Microstructure of a) Nickel alloy matrix, b) Ni-alloy $+9 \% \mathrm{Al}_{2} \mathrm{O}_{3}+9 \% \mathrm{TiO}_{2}$ hybrid composites.

\section{Coefficient of Thermal Expansion (CTE)}

The compatibility of its material properties is the important property of composite materials. The composite materials thermal expansion coefficient (CTE) plays an important role in its application. It is known that between the matrix phase and the reinforcements, often there is a state of microtubules. The adjustment in the individual stage thermal extension causes pressure which is a roundabout way influences the properties of the composite. It is hard to completely summarize the coefficient of thermal extension of a metal lattice grid, with specific variables influencing it. The coefficient of thermal expansion (CTE) addresses the estimation of changes in material with temperature. The proportion of CTE material in its constituent particles is associated with the imperativeness of the bond in it. In the current investigation, at various temperatures, the coefficient of thermal expansion was ascribed to nickel combination composites with equivalent measures of reinforcements weight $\left(\mathrm{Al}_{2} \mathrm{O}_{3} / \mathrm{TiO}_{2}\right)$. The consequence of the experiment was that the thermal coefficient for both nickel materials (base metal) and nickel composites materials $\left(\mathrm{Al}_{2} \mathrm{O}_{3} / \mathrm{TiO}_{2}\right)$ decreased with increasing temperature. The diagram (Figure 4) shows that the CTE for the base nickel alloy composites with reinforcements changes from 15.5 to 9.2 in any case and that the CTE base nickel alloy hybrid composite with the expansion temperature decreased from $3 \%$ to $12 \%$ by weight. Figure 4 shows that as the reinforcing material increases, the CTE gradually drops by a certain temperature to 12 percent $\mathrm{Al}_{2} \mathrm{O}_{3}$ weight and 9 percent $\mathrm{TiO} 2$ weight. The update ratio hits its minimum value and then decreases by 12 percent as material improvements begin at the rate of reinforcements. The CTE value decreases the importance of aggregation and reinforcement clustering (as microstructural observations show). Thus, 12 percent weight is used to get at minimum CTE from a composite perspective. Figure 4 further indicates that the maximum CTE (15.5) is obtained at nickel alloy and lower CTE (9.2) for hybrid composites, despite the reinforcements. Therefore, it is concluded that the hybrid MMCs and temperature reinforcement's factors affect the CTE of the developed nickel alloy HMMCs.

\section{Thermal Conductivity of Hybrid Composites}

It is well known that physical dimensions change when an object is heated. This is due to the expanded development of high-temperature component atoms. An increase in temperature forces these molecules to maintain a normal separation significantly above low temperatures. The linear thermal expansion, as a function of temperature, is used to determine the rate at which an object will elongate. This experiment may be used for design purposes and to determine whether there is a thermal stress disorder. Knowledge of the relative production characteristics of the two materials is essential. In this composite material, the investigation of thermal conductivity is estimated at different temperatures for various values of nickel combinations, with various rates of the steady weight of $\mathrm{Al}_{2} \mathrm{O}_{3}$ and $\mathrm{TiO}_{2}$. The expansion in the weight level of $\mathrm{Al}_{2} \mathrm{O}_{3} / \mathrm{TiO}_{2}$ the thermal conductivity also increments as the temperature rises. Figure 4 shows that the thermal conductivity for the nickel composite changes at different temperatures of $36.57 \mathrm{~W} / \mathrm{m}{ }^{\circ} \mathrm{C}$ 
without reinforcement. The highest thermal conductivity observed for the nickel junction structure was $58.39 \mathrm{~W} / \mathrm{m}{ }^{\circ} \mathrm{C}$ in 9 wt. $\% \mathrm{Al}_{2} \mathrm{O}_{3} / \mathrm{TiO}_{2}$ hybrid composite materials, and the basic thermal conductivity was $36.57 \mathrm{~W} / \mathrm{m}{ }^{\circ} \mathrm{C}$. Despite the temperature, the thermal conductivity increased up to 9 weight percentage of $\mathrm{Al}_{2} \mathrm{O}_{3} / \mathrm{TiO}_{2}$ with increasing the reinforcement content from the plot. For reinforcements greater than 9 percent weight thermal conductivity is decreased despite the aggregation of reinforcements (as is evident from microstructural observation). The decrease in thermal conductivity was in the ceramic phases, i.e. the reinforcements at 12 percent weight in the ductile phase of $\mathrm{Al}_{2} \mathrm{O}_{3}$ and 9 percent $\mathrm{TiO}_{2}$ with hybrid composites of a nickel alloy. However, it was concluded that thermal conductivity is affected by the temperature content and the reinforcement. In this research, the thermal conductivity of nickel alloy hybrid MMCs ( $58.39 \mathrm{~W} / \mathrm{m}$ degrees $\mathrm{C})$ is again observed to be higher than that of steel $(45 \mathrm{~W} / \mathrm{m}$ degrees $\mathrm{C})$.

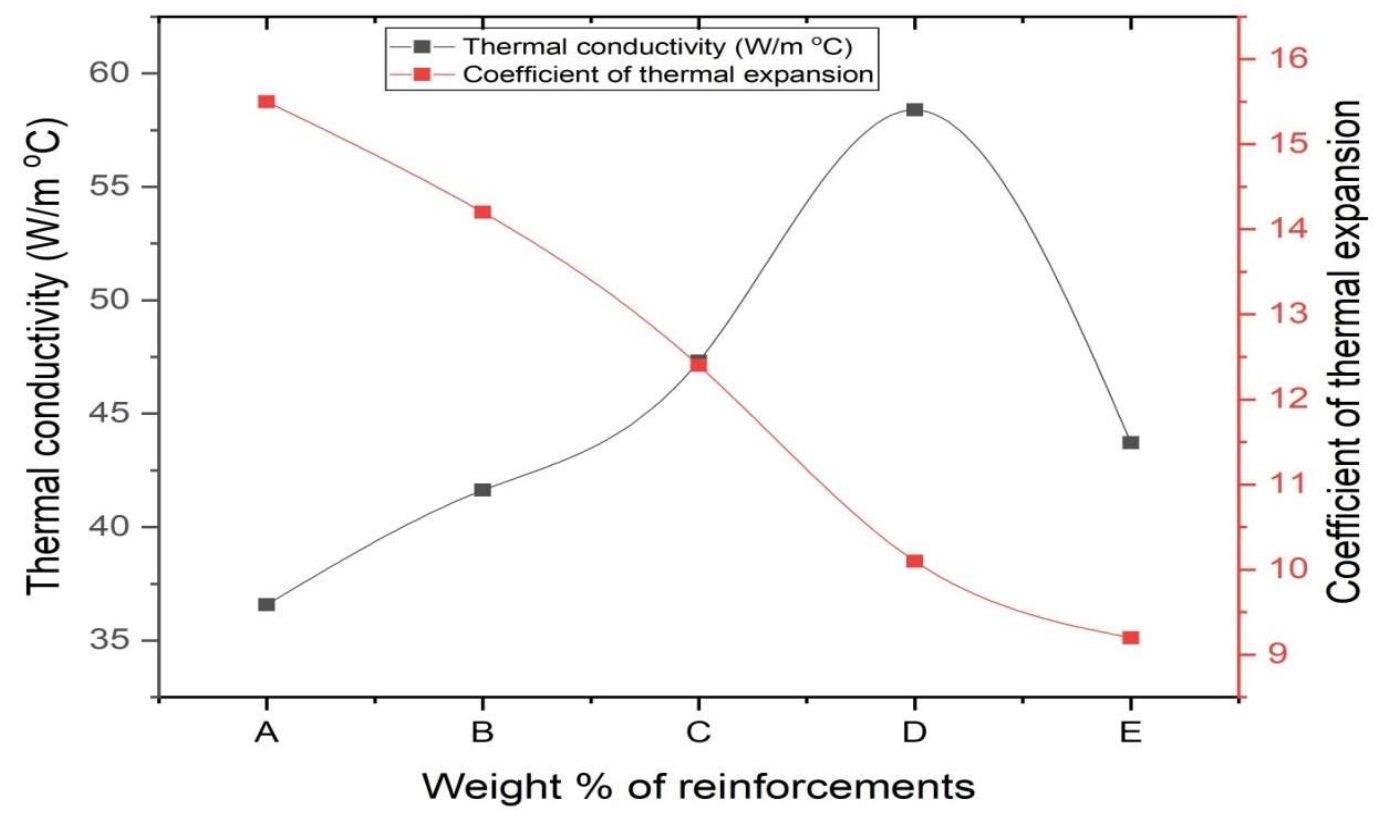

Figure 4. Thermal conductivity and coefficient of thermal expansion with weight $\%$ of reinforcements.

\section{Temperature Distribution Analysis of Nickel alloy Hybrid Metal Matrix Composites for IC Engine Exhaust Valve Operating temperature of exhaust valve}

The internal combustion engine valves are parts of the precision engine. Valves are opened and closed at appropriate times. The approaching change is driven by the channel valves, and the exhaust gases are discharged into nature through the exhaust valves. They are often used against the manifolds to protect the working space within the cylinders. Any kind of valve failure affects engine performance, making it necessary to give the failure analysis of the internal combustion engine valves outstanding importance. Available work on valve failures reveals that the design of the valve is an uncomfortable task because the valve at any given time has differentiated lots. Otto and Diesel's engines work inside the admission valve at temperatures of $550{ }^{\circ} \mathrm{C}$, the associated characteristics of the fumed valve are respectively $700{ }^{\circ} \mathrm{C}$ and $800^{\circ} \mathrm{C}$. In view of the compression ratio, the exhaust valve temperature will shoot down to $900{ }^{\circ} \mathrm{C}$. Available at very high temperatures, valves are subjected to cyclic charge and are caused by elastic and plastic deformation, and fatigue in most cases, by a failure of the conical valve surface. The stem of the exhaust valve typically fails to overheat since the exhaust valve temperature is around $720^{\circ} \mathrm{C}$. Valve stem fracture surface is protected by the development of a black oxide layer, and a fatigue surface is smooth and is filled with dense oxide or particles that are not easily soluble. Longitudinal fret damage can occur in the middle portion of the stem. Any minor cracks are introduced in the section and propagated. Due to the heavy load, several cracks are triggered if the valves are exposed to high temperatures and it is rational to anticipate failure within a few million cycles under these operating conditions. 
The material properties (Table 01) for the FE analysis are specified following the properties of the developed composites (matrix and reinforcements) and the boundary conditions following the prevailing conditions of the combustion chamber of the internal combustion engine.

Table 1. Physical properties of materials

\begin{tabular}{lccc}
\hline Materials Properties & $\begin{array}{c}\text { Nickel alloy } \\
(\mathbf{N i} \text { alloy) }\end{array}$ & $\begin{array}{c}\text { Aluminum Oxide } \\
\left(\mathbf{A l}_{\mathbf{2}} \mathbf{O}_{\mathbf{3}}\right)\end{array}$ & $\begin{array}{c}\text { Titanium Dioxide } \\
\mathbf{( T i O}_{\mathbf{2}} \mathbf{)}\end{array}$ \\
\hline Crystal Structure & $\mathrm{FCC}$ & $\mathrm{FCC}$ & $\mathrm{HCP}$ \\
Melting Point ${ }^{\circ} \mathrm{C}$ & 1455 & 2072 & 1844 \\
Tensile Strength (MPa) & 450 & 296 & 333 \\
Density (g/cc) & 8.8 & 3.9 & 4.24 \\
Young's Modulus (GPa) & 179 & 370 & 230 \\
Poisson's Ratio & 0.31 & 0.22 & 0.27 \\
Hardness (VHN) & $110-138$ & 560 & 951 \\
Thermal Conductivity (W/m-K) & 60.7 & 38.5 & 11.8 \\
Coefficient of Thermal Expansion & 12 & 10.9 & 11.8 \\
$\left(10^{-6} / \mathrm{K}\right)$ & & & \\
\hline
\end{tabular}

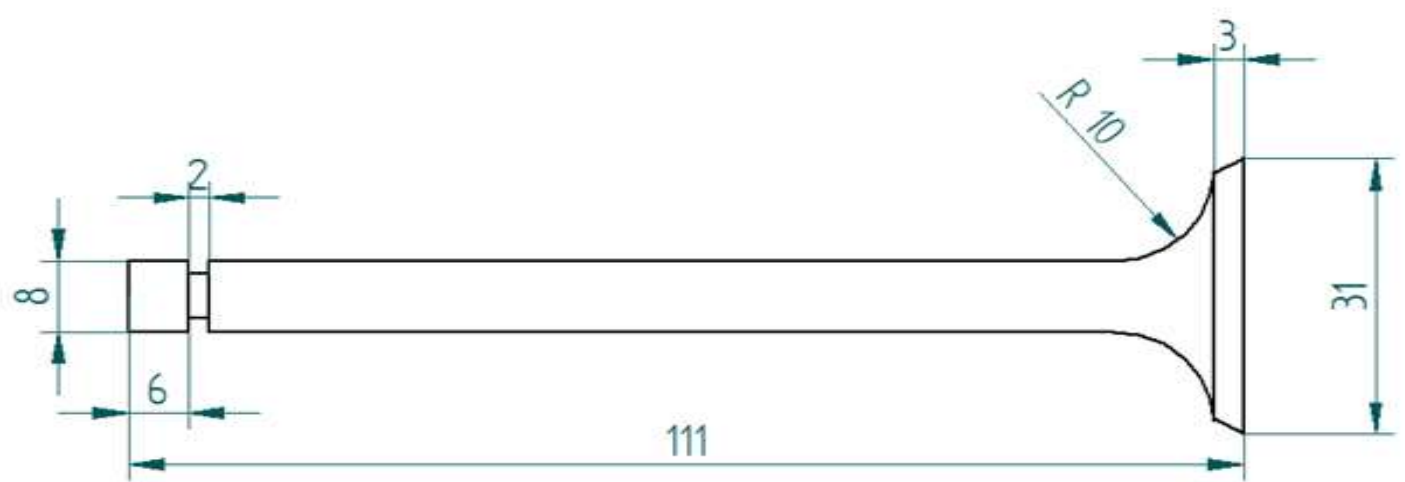

All dimensions in $\mathrm{mm}$

Figure 5. I C engine exhaust valve 2D model drawing.

Figure 5 and 6 shows the standard IC engine exhaust valve of 2D and meshing of I C engine exhaust valve and mesh attributes at locations of I $\mathrm{C}$ engine valve for $\mathrm{FE}$ analysis. The mesh cell type is tetrahedral and number of cells used is 41897 . The mesh show is common for all cases and mesh quality checks were conducted to ensure the results accuracy. The element quality was maintained nearly to 1 which is the maximum quality for the elements. Fine mesh is captured at the critical areas and tetrahedral cells are used to capture the curvature of the valve perfectly and obtain accurate results. Work age is the act of making a work, a development into discrete geometric and topological cells of a nonstop geometric space. The phones for the most part segment the information space geometrically. Work cells are applied to the bigger area as discrete nearby approximations. Lattices are made by PC calculations, frequently through a graphical UI with human direction relying upon the unpredictability of the area and the sort of work wanted. The point is to make a work that precisely catches the geometry of the information space, with great (very much formed) cells, and without such a large number of cells that resulting figuring become obstinate. In territories which are significant for the ensuing counts, the work ought to likewise be fine (have little components). 

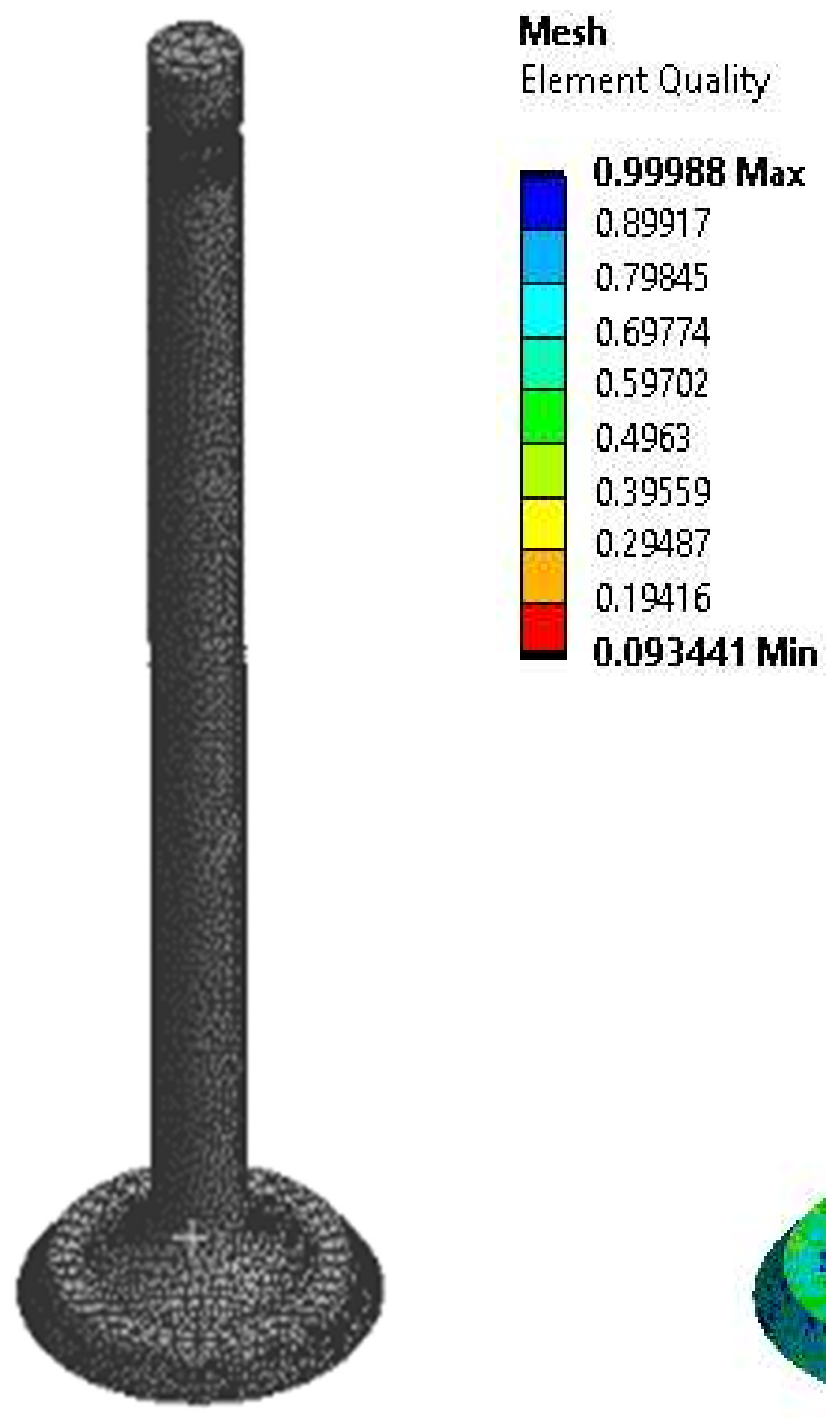

Figure 6. The meshing of I C engine exhaust valve.

\section{Analysis of the exhaust valve}

Temperature distribution and heat flux (Figure 7) for base nickel alloy (without reinforcement) composites are along the valve length. The temperature contour for the alloy of base metal nickel is shown to range from $60.45^{\circ} \mathrm{C}$ to $570{ }^{\circ} \mathrm{C}$. The maximum temperature occurs at the bottom end as high temperature occurs during engine combustion and this valve has to be opened and the exhaust has to be released. Similarly, thermal analysis was carried out for the other combinations of the hybrid nickel alloy metal matrix composites and appropriate material is chosen for the Exhaust valve. Heat flux or power of heat stream rate is stream vitality per unit region per unit time. To characterize the heat transfer at a given point in space, one takes the restricting situation where the surface size turns out to be imperceptibly little. For the base metal nickel alloy, the heat flux contour is shown to range from $1861.1 \mathrm{~W} / \mathrm{m}^{2}$ to $3.8176 \times 10^{5} \mathrm{~W} / \mathrm{m}^{2}$. The Maximum heat flux is found at the intersection of the stem head and the heat flow occurs in this region. 


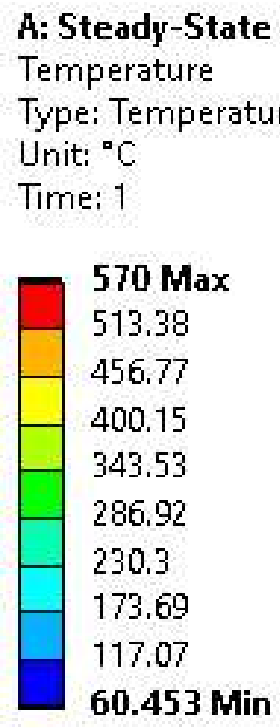

A: Steady-State Thermal

Total Heat Flux

Type: Total Heat Flux Unit: $W / m^{2}$

Time: 1

\begin{tabular}{|l}
$\mathbf{3 . 8 6 3 6 e} 5 \mathrm{Max}$ \\
$3.4357 \mathrm{e} 5$ \\
$3.0078 \mathrm{e} 5$ \\
$2.5798 \mathrm{e} 5$ \\
$2.1519 \mathrm{e} 5$ \\
$1.724 \mathrm{e} 5$ \\
$1.296 \mathrm{e} 5$ \\
86809 \\
44015 \\
$\mathbf{1 2 2 1 . 6}$ Min
\end{tabular}

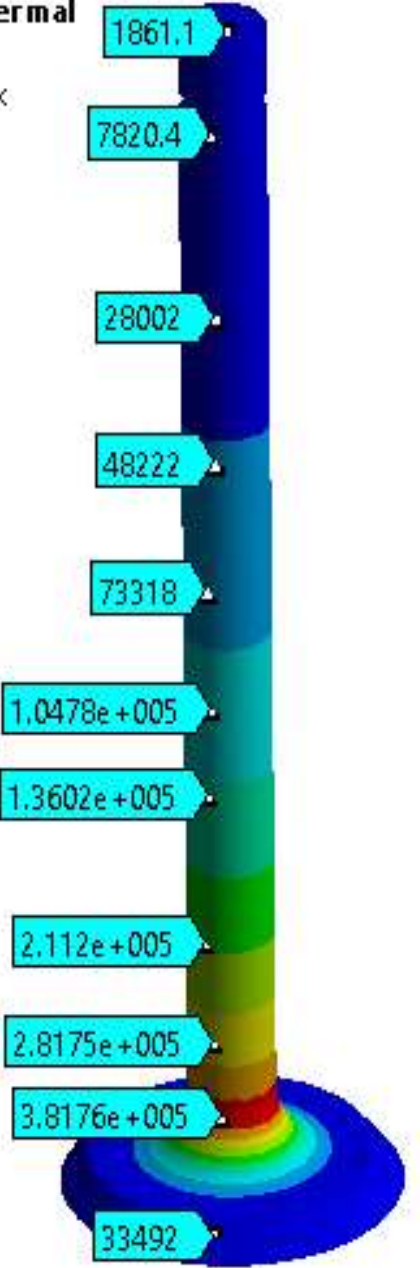

Figure 7. Temperature distribution and heat flux of unreinforced nickel alloy composites.

Figures 8-11 show the temperature distribution and heat flow along the length of the valve for the base nickel alloy $+3 \% \mathrm{Al}_{2} \mathrm{O}_{3}+9 \% \mathrm{TiO}_{2}$, nickel alloy $+6 \% \mathrm{Al}_{2} \mathrm{O}_{3}+9 \% \mathrm{TiO}_{2}$, nickel alloy $+9 \% \mathrm{Al}_{2} \mathrm{O}_{3}+9 \% \mathrm{TiO}_{2}$ and nickel alloy $+12 \%+\mathrm{Al}_{2} \mathrm{O}_{3}+9 \%+\mathrm{TiO}_{2}$ hybrid metal matrix composite materials. It can be seen from figures 11 to 14 that the temperature of the valve tip approximately varies from $60{ }^{\circ} \mathrm{C}$ to $63{ }^{\circ} \mathrm{C}$ towards the valve base. On account of a base nickel composite without reinforcements, the base temperature was $555.93{ }^{\circ} \mathrm{C}$, trailed by $699.32{ }^{\circ} \mathrm{C}$ for $3 \%$ by weight $\mathrm{Al}_{2} \mathrm{O}_{3}$ and $9 \%$ by weight $\mathrm{TiO}_{2}, 859.21^{\circ} \mathrm{C}$ for $6 \%$ by weight $\mathrm{Al}_{2} \mathrm{O}_{3}$ and $9 \%$ by weight $\mathrm{TiO}_{2}, 959.68{ }^{\circ} \mathrm{C}$ for $9 \%$ by weight $\mathrm{Al}_{2} \mathrm{O}_{3}+\mathrm{TiO}_{2}$ and $583.97{ }^{\circ} \mathrm{C}$ for 12 wt. $\% \mathrm{Al}_{2} \mathrm{O}_{3}$ and 9 wt. $\% \mathrm{TiO}_{2}$ expansion of reinforcements. It is also observed from the temperature distribution contour that the temperature which extended monotonically from tip to put together and, by nickel combination without stronghold was $46^{\circ} \mathrm{C}$ and by nickel mix, 3 wt. percent to 12 wt. percent of $\mathrm{Al}_{2} \mathrm{O}_{3}$ and consistent 9 wt. percent of $\mathrm{TiO}_{2}$ composites, $43{ }^{\circ} \mathrm{C}$ and $42{ }^{\circ} \mathrm{C}$ independently. This shows reinforcements affect temperature dispersion. The figures again show that the most elevated base temperature $\left(959.68{ }^{\circ} \mathrm{C}\right)$ was recorded for base nickel composites at 9 wt. percent of $\mathrm{Al}_{2} \mathrm{O}_{3} / \mathrm{TiO}_{2}$ fortified hybrid composites because of an expansion in thermal conductivity of $58.39 \mathrm{~W} / \mathrm{m}{ }^{\circ} \mathrm{C}$ and reduced to $583.97{ }^{\circ} \mathrm{C}$ for 12 wt. percentage of $\mathrm{Al}_{2} \mathrm{O}_{3}$ and 9 wt. percent of $\mathrm{TiO}_{2}$ hybrid composites due to solid interfacial bonding with agglomeration between the matrix and reinforcements of $\mathrm{Al}_{2} \mathrm{O}_{3}$ $/ \mathrm{TiO}_{2}$ as evidenced by microstructural observation. Similarly, the rate of heat flux increases from 1861.1 to $7.9336 \mathrm{x}$ $10^{5} \mathrm{~W} / \mathrm{m}^{2}$ in nickel alloy with 3 wt. percent of $\mathrm{Al}_{2} \mathrm{O}_{3}$ and is constant for 9 wt. percent of $\mathrm{TiO}_{2}$ reduces at 12 wt. percentage of $\mathrm{Al}_{2} \mathrm{O}_{3}$ and 9 wt. percentage of $\mathrm{TiO}_{2}$ due to the effect of temperature on hybrid composites. 
Journal of Thermal Engineering, Research Article, Vol. 7, No. 3, pp. 415-428, March, 2021
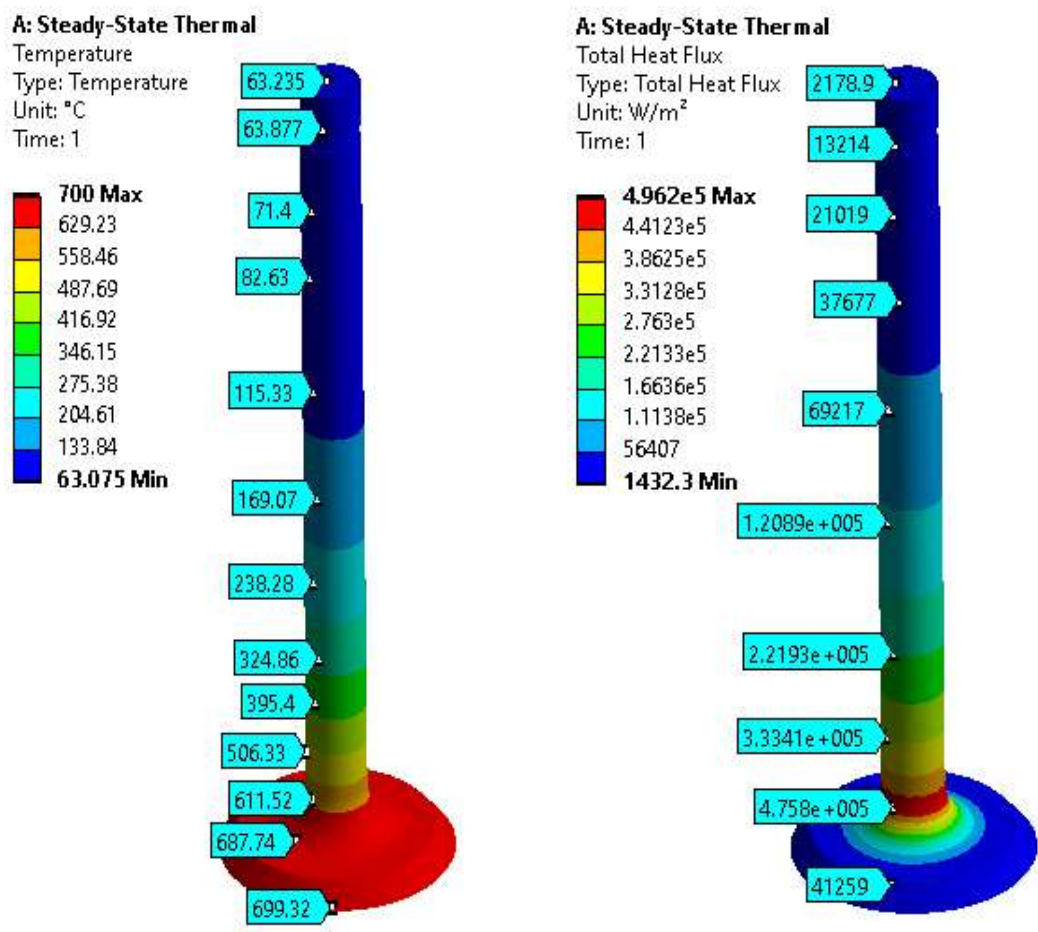

Figure 8. Temperature distribution and heat flux of nickel alloy with 3 wt. $\% \mathrm{Al}_{2} \mathrm{O}_{3}$ and 9 wt. $\% \mathrm{TiO}_{2}$ hybrid composites.
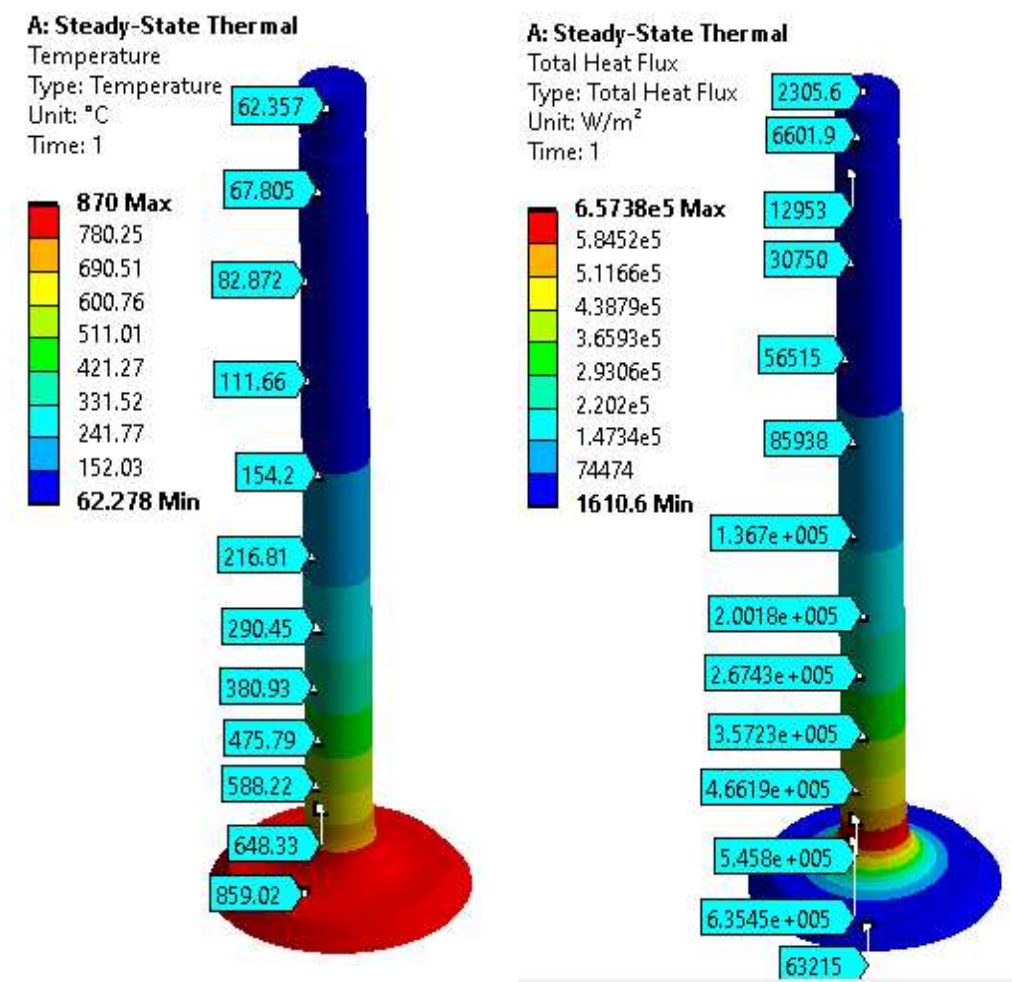

Figure 9. Temperature distribution and heat flux of nickel alloy with 6 wt. $\% \mathrm{Al}_{2} \mathrm{O}_{3}+9$ wt. $\% \mathrm{TiO}_{2}$ hybrid composites. 
In this study, it is observed that nickel composite MMCs can be used as electrical materials for valves of internal combustion engines, and reinforcements affect the temperature transfer, for example, the temperature of the base temperature increments, when the substance of the reinforcements increments. Regardless of the above, the IC engine steam valves currently used are made of composite steel ( $\mathrm{Ni}-\mathrm{Cr}$ ) and have to work at a working temperature of $650{ }^{\circ} \mathrm{C}$. Due to their activity, they are also exposed to cyclic stacking should have sufficient strength and wear-resistant. However, the present hybrid nickel MMCs developed by the embedding of $\mathrm{Al}_{2} \mathrm{O}_{3} / \mathrm{TiO}_{2}$, have all the properties mentioned above; nickel alloy and $\mathrm{Al}_{2} \mathrm{O}_{3} / \mathrm{TiO}_{2}$ are fatigue-proof and wear-resistant. The data of the standard manufacturers of internal combustion engines (Escorts and Goetz Ltd., CAR mobiles Ltd., India) regarding temperature distribution and valve properties agree with the nickel alloy hybrid MMCs developed in the present study. It should be noted here that the durability of nickel alloy hybrid composite materials is greater than that of alloy steel (235 and $216 \mathrm{BHN})$ and the density of the nickel alloy is also greater than that of steel $\left(8.9\right.$ and $\left.7.85 \mathrm{~g} / \mathrm{cm}^{3}\right) \mathrm{with} \mathrm{a}$ tensile strength of $650 \mathrm{MPa}$. The current nickel alloy can therefore, be conveniently used for internal combustion engines.

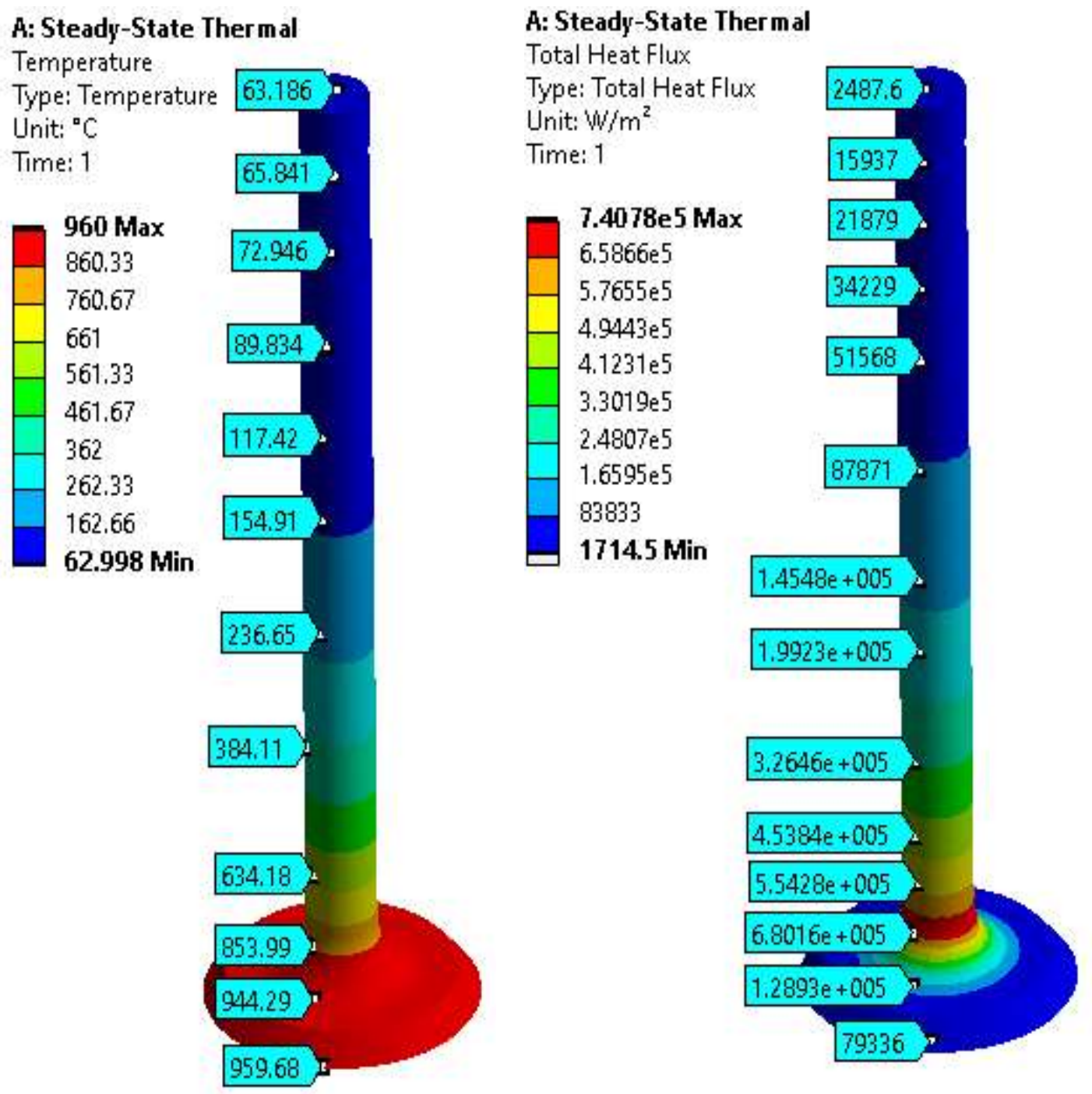

Figure 10. Temperature distribution and heat flux of nickel alloy with 9 wt. $\% \mathrm{Al}_{2} \mathrm{O}_{3}+9$ wt. $\% \mathrm{TiO}_{2}$ hybrid composites. 


\section{CONCLUSION}

This research work promotes the production of nickel alloy composite grade ASTM A494 M with different $\mathrm{Al}_{2} \mathrm{O}_{3}$ additives starting at $3 \mathrm{wt}$. percent to $12 \mathrm{wt}$. percent, $9 \mathrm{wt}$. percent of $\mathrm{TiO}_{2}$. The sand casting method is used to develop hybrid composites through an induction furnace with an agitation process. The result of the present research is based on empirical results and discussions are as follows:

- The microstructural assessment shows that the support particles are equitably conveyed in the composite materials and no interface responses are seen at higher amplification. Specifically, the mixing impact during cementing has affected the microstructures. Likewise, the expansion of $\mathrm{Al}_{2} \mathrm{O}_{3} / \mathrm{TiO}_{2}$ impacted the morphology of the nickel combination. The microstructure of hybrid composite materials is better than that of unreinforced network composites with an even appropriation of $\mathrm{Al}_{2} \mathrm{O}_{3} / \mathrm{TiO}_{2}$ particles.

- The base alloy nickel alloy has a lower thermal conductivity, but the thermal conductivity increases to the maximum temperature for the different percentage compositions of hybrid MMCs for the base metal matrix, by reinforcing with $\mathrm{Al}_{2} \mathrm{O}_{3}$ and $\mathrm{TiO}_{2}$. The weight percentage of reinforcements increases with an increase in thermal conductivity up to 9 percent of $\mathrm{Al}_{2} \mathrm{O}_{3} / \mathrm{TiO}_{2}$ hybrid composites.

- The reduction in the CTE rating was identified by an improvement in the reward level to a 12 percent weight percentage and the effects of ceramic phase reinforcements $\left(\mathrm{Al}_{2} \mathrm{O}_{3} / \mathrm{TiO}_{2}\right)$ in the ductile matrix (FCC). Maximum CTE is also observed at the highest temperature of 9 percent by weight percent of $\mathrm{Al}_{2} \mathrm{O}_{3} / \mathrm{TiO}_{2}$ and the minimum nickel alloy without reinforcements.

- The analysis of the $\mathrm{FE}$ shows that the reinforcements greater influence the temperature distribution. The highest base temperature $\left(958.68{ }^{\circ} \mathrm{C}\right)$ was reported for the $\mathrm{Al}_{2} \mathrm{O}_{3} / \mathrm{TiO}_{2}$ hybrid composites at a weight of 9 percent and decreases from 12 percent by weight to $583.97{ }^{\circ} \mathrm{C}$ for $\mathrm{Al}_{2} \mathrm{O}_{3}$ and a constant of 9 percent by weight for $\mathrm{TiO}_{2}$ composite materials and $555.93^{\circ} \mathrm{C}$ for non-reinforced nickel alloys.

\section{NOMENCLATURE}

$K \quad$ Thermal conductivity, $\mathrm{W} / \mathrm{m}-\mathrm{k}$

$\sigma \quad$ Electrical conductivity, $\mathrm{S} / \mathrm{m}$

$\alpha_{v} \quad$ Thermal expansion coefficient, $\left(\mathrm{K}^{-1}\right)$

\section{REFERENCES}

[1] Joel Hemanth, Development of Nickel Alloy Reinforced with Fused SiO2 Chilled Composites and Evaluation of Thermal Properties (Thermal Conductivity \& Coefficient of Thermal Expansion) and Temperature Distribution by Finite Element Analysis (FEA). Open Journal of Composites Materials. 2017; 7(5): 251-264.

[2] Purushotham G, Joel Hemanth. Influence of fused Silica and chills incorporation on Corrosion, Thermal and Chemical composition of ASTM A 494 M Grade Nickel alloy. IOP Conf. Ser.: Materials Science and Engineering. 2016; 149-012042: 1-13. https:// doi.org/10.1088/1757-899X/149/1/012042

[3] Trzepiecinski T, Lemu HG. Frictional Resistances of AMS5599 Nickel-based Alloy at High Pressure Conditions IOP Conf. Ser.: Materials Science and Engineering. 2018; 381-012159:1-7. https:// doi.org/10.1088/1757-899X/381/1/012159.

[4] Joel Hemanth, Corrosion Behavior of Nickel Alloy (ASTM A 494 M) Reinforced with Fused SiO2 Chilled Metal Matrix Composites (MMCs) for Marine Applications. Materials Science and Engineering. 2017; 225012192:1-7. https:// doi.org/10.1088/1757-899X/225/1/012192

[5] Purushotham G, Joel Hemanth. Study of Physico-Chemical Properties of Monel M-35-1 Nickel Alloy-Fused Silica Metal Matrix Composite for Marine Application. Indian Journal of Advances in Chemical Science. 2016; 4(3): 235-240.

[6] Nelson AT., White JT, Anderson DA.Thermal Expansion, Heat Capacity and Thermal Conductivity of Nickel Ferrite (NiFe2O4). The American Ceramic Society, 2014; 4: 1-7. https://doi.org/10.1111/jace. 12901

[7] Zielińska M, Yavorska M, Poręba M, Sieniawski J. Thermal properties of cast nickel based superalloys. Archives of Materials Science and Engineering. 2010; 44(1): 35-38.

[8] El-Bagoury N, Mohammed A. Amin, Mohsen Qhatani, Effect of Various Heat Treatment Conditions on Microstructure, Mechanical Properties and Corrosion Behavior of Ni-base Superalloys. Int. J. Electrochem. Sci., 2011; 6(12): 6718-6732.

[9] Meenu Srivastava, Srinivasan A, William Grips V K. Influence of Zirconia Incorporation on the Mechanical 
and Chemical Properties of Ni-Co Alloys. American Journal of Materials Science. 2011; 2:113-122. https:// doi.org/10.5923/j.materials.20110102.19

[10] Durul Ulutan, Tuğrul Özel. Machining-Induced Surface Integrity in Titanium and Nickel alloys: A Review. International Journal of Machine Tools \& Manufacture. 2011; 51:250-280. https:// doi.org/10.1016/j.ijmachtools.2010.11.003

[11] Calin, Recep, Muharrem Pul, and Zühtü Onur Pehlivanli. The effect of reinforcement volume ratio on porosity and thermal conductivity in Al-Mgo composites. Materials Research. 2012; 15(6): 1057-1063.

[12] X D Liu, J S Zhang, X M Cao, H Zhang. Finite element simulation of the thermal properties of particulate and continuous network-reinforced metal-matrix composites. Proc.Imech, Part B: Journal of Engineering Manufacture, 2005; 219(1): 111-121. https://doi.org/10.1243/095440505X8055

[13] Zahra Fattahi, Seyed Abdolkarim Sajjadi, Abolfazl Babakhani, Farhad Saba. Ni-Cr matrix composites reinforced with nano and micron sized surface-modified zirconia: Synthesis, microstructure and mechanical properties. Journal of Alloys and Compounds. 2020;817:15275. https://doi.org/10.1016/j.jallcom.2019.152755

[14] Cem Okumus S, Serdar Aslan. Ramazan Karslioglu, Deniz Gultekin, Hatem Akbulut. Thermal Expansion and Thermal Conductivity Behaviors of Al-Si/SiC/graphite Hybrid Metal Matrix Composites (MMCs). Materials Science (Medziagotyra). 2012; 18(4):341-346. http://dx.doi.org/10.5755/j01.ms.18.4.3093

[15] Davis LC, Artz BE. Thermal conductivity of metal matrix composites. Journal of Applied Physics. $1995 ; 77$ (10): 4954-4960.

[16] Matine A, Boyard N, Cartraud P, Legrain G, Jarny Y. Thermal properties of composite materials: effective conductivity tensor and edge effects. J. Phy. Conf. Ser., 2012; 395-012014:1-9. doi:10.1088/17426596/395/1/012014

[17] Sunil Kumar Reddy K, Kannan M, Karthikeyan R, Laxman B. Evaluation of thermal and mechanical properties of A17475 alloy reinforced with SiC and graphite. Materials Today: Proc. 2020; 26(2): 2691-2696. https://doi.org/10.1016/j.matpr.2020.02.566 